\title{
MIOCLONIAS VELO-FARINGO-LARINGEAS
}

\section{JOSE ZACLIS *}

Observando um caso de síndrome mioclônica velo-faringo-laringea, tivemos a oportunidade de obter o registro gráfico e cinematográfico dêsses movimentos, que foram descritos pela primeira vez por Küpper em 1873. Em 1886, Spencer descreveu o mesmo quadro hipercinético sob a denominação de nistagmo da faringe e laringe. $\mathrm{Em}$ contraposição aos autores que admitiam a existência de uma fase lenta e uma rápida em cada um dos movimentos, Guillain e Mollaret ${ }^{1}$, revendo observações publicadas, verificaram que os traçados apresentados demonstram, pelo contrário, que as duas fases são idênticas. Não será discutida, neste trabalho, a propriedade ou impropriedade das denominaçōes dadas por diferentes autores a essa hipercinesia; apenas queremos salientar que o gráfico obtido constitui prova evidente de que, pelo menos neste caso, cada movimento se compõe de duas fases com velocidades diferentes.

A. B., 29 anos, preto, brasileiro, internado na Clínica Neurológica do Hospital das Clínicas em junho de 1946. Trata-se de paciente que, na vigência de processo infeccioso agudo, com hipertermia $\left(39-40^{\circ} \mathrm{C}\right)$, anorexia, arrepios de frio e icterícia, que datava de um mês, apresentou, sùbitamente, em 11 de abril de 1946, hemiplegia direita. Nessa ocasião, êle se achava internado em uma das enfermarias de Clínica Médica do Hospital das Clínicas, tendo sido feito o diagnóstico provável de abscesso no hemisfério cerebral esquerdo, baseado em dados clínicos e liquóricos.

O exame neurológico revelou hemiplegia espasmódica direita total e desproporcionada, com predomínio no membro superior, afasia mista de tipo Broca com predominância do contingente motor, sialorréia abundante, reflexo de retração da cabeça (head retraction reflex) bem evidente. Além disso, notavam-se movimentos involuntários espontâneos atingindo diversos segmentos corpóreos, que passamos a descrever: 1 - oscilação arrítmica da cabeça no plano sagital, com velocidade e amplitude variáveis, sendo de $10^{\circ}$, aproximadamente, a amplitude máxima; 2 movimentos rítmicos de elevação e abaixamento da laringe, perceptíveis à inspeção e pela palpação, sôbre um plano ligeiramente inclinado de cima para baixo e de trás para frente, com freqüência de 140 por minuto e amplitude de $0,5 \mathrm{~cm}$, aproximadamente: $3 \rightarrow$ no pálato mole $e$ na faringe, movimentos síncronos 2 harmônicos com os observados externamente no laringe; cada período podia se: decomposto em duas componentes diferentes entre si pela velocidade; na fase rápida, o véu se abaixava do lado esquerdo, os pilares do mesmo lado se encurtavam e arrastavam em sua direção a parede posterior da faringe; na fase lenta produzia-se deslocamento em sentido oposto: o véu voltava à posição inicial (úvula na linha mediana), os pilares se alongavam e se afastavam da linha mediana, voltando a parede posterior da faringe à posição de repouso; a metade direita do

* Assistente de Neurologia na Fac. Med. Univ. S. Paulo (Prof. A. Tososa).

1. Guillain, G. e Mollaret, P. - Les syndromes myocloniques synchrones e rythmés velo-pharyngo-laryngo-oculo-diaphragmatiques. Presse Méd. 1:57-60 (janeiro) 1925. 
véu e faringe era deslocada passivamente; 4-pelo exame laringoscópico (Dr. J. Rezende Barbosa), foram vistos movimentos idênticos, com as mesmas caraterísticas de frequeência, duração e amplitude no hemilaringe esquerdo; 5 - o membro superior esquerdo, estendido perpendicularmente ao plano frontal ou sagital, exibia movimentos sucessivos de elevação e abaixamento, arrítmicos e irregulares, variáveis em tempo e amplitude. Semelhantes movimentos eram também perceptíveis em ambos os membros inferiores postos na posição para a prova de Mingazzini.

O exame radioscópico simples e contrastado mostrou estar o diafragma livre de quaisquer movimentos anormais. Os músculos oculomotores também moviinentavam-se normalmente, não exibindo nistagmo, nem mioclonias.

Em virtude da afasia, não pudemos julgar seguramente se a hipercinesia laríngea exercia influência sôbre a palavra; no período final de sua internação no hospital, quando já havia recuperação na articulação de sílabas, tivemos a impressão de que tal influência não existia.

Para facilitar a exposição, reuniremos os movimentos descritos nos diversos segmentos em grupos, colocando em um dêles os verificados no pálato mole, faringe e laringe, e, no outro, aquêles da cabeça e membros. Os do primeiro grupo são perfeitamente identificáveis à síndrome mioclônica que, segundo o conceito de Foix e seus colaboradores $^{2}$, dependeria da lesão do feixe central da calota, conceito mais tarde modificado por Guillain e Mollaret, que admitem responsável pela síndrome a lesão da oliva bulbar, do núcleo denteado do cerebelo ou das vias de associação entre êsses dois núcleos. São movimentos rítmicos, de alta freqüência, invariáveis com as diversas posições e atitudes do paciente e sôbre os quais a vontade não exerce a mínima influência.

Os gráficos* (figuras 1, 2, 3 e 4) obtidos por intermédio de um tambor de Marey aplicado à face anterolateral esquerda do pescoço do paciente, na altura da cartilagem tireóide, mostraram ondas de contração intercaladas por espaços de inatividade muscular, sendo possível distinguir, em cada onda, uma fase ascendente, mais rápida, e uma descendente, mais lenta. A proporção cronológica entre a fase de atividade muscular e a de repouso é aproximadamente $1: 2$; a duração das fases ascendente e descendente é expressa pela razão $3: 5$, aproximadamente. O traçado simultâneo da respiração, pulso e dos movimentos observados no segmento cervical, afastam a hipótese de poderem êstes últimos representar transmissão de batimentos arteriais.

2. Foix, Ch., Chavany, J. A. e Hillemand, P. - Le syndrome myoclonique de la calotte. Cturae anatomo-clinique du nistagmus du voile et des myoclonies rythmiques associćes, oculaires, faciates, etc. R. Neurol. 1:942-945 (junho) 1926.

- Agradecemos ao Dr. Joaquim Lacaz, do Departamento de Fisiologia da Faculdade de Medicina de São Paulo, pela assistência téenica na execução dos traçados. 
FIG. 1 - Traçado simultâneo dos movimentos mioclónicos (M), pulso (P) e respiração ( $R$ ). Notar que as ondulações

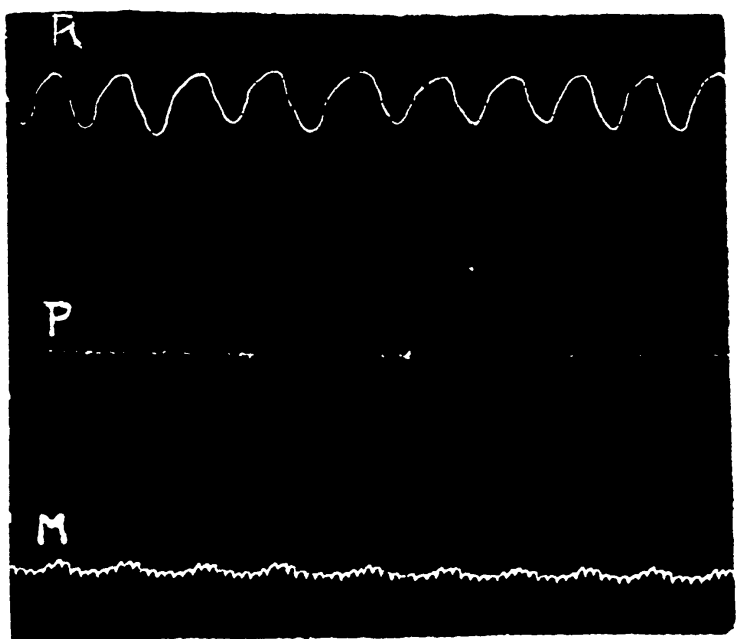
amplas existentes no traçado das mioclonias correspondem aos movimentos respiratórios.

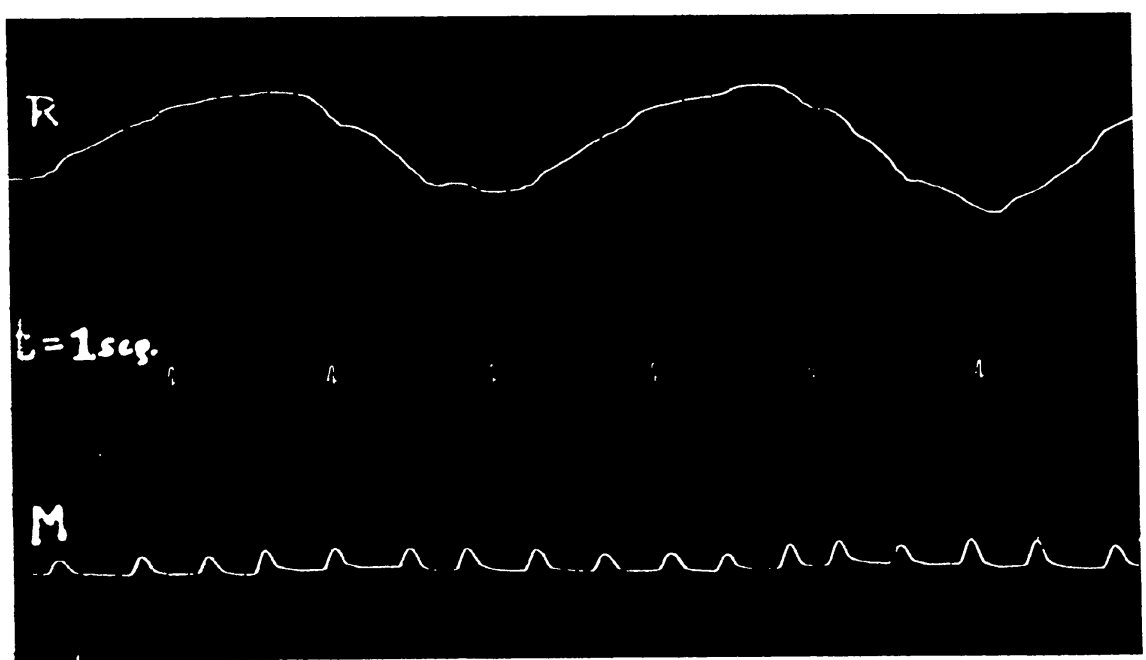

FIG. 2 - Registro gráfico da respiração (R) e das mioclonias (M) para mostrar as caraterísticas dos movimentos mioclonnicos. 


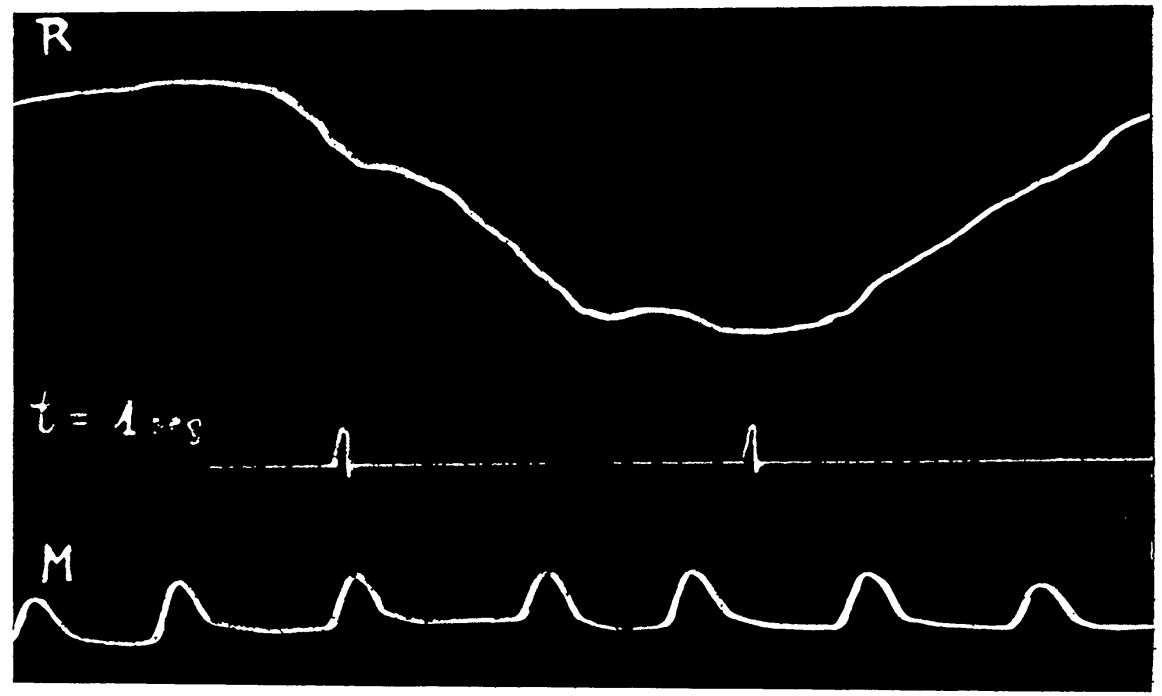

Fig. 3 - Ampliação da figura 2. Notar a duração diferente das fases ascendentes e descendentes das mioclonias.

Quanto aos movimentos verificados no pescoço e membros, irregulares, sem rítmo, julgamos tratar-se de instabilidade postural fisiológica que se manifesta nas atitudes forçadas, acentuada neste caso por debilitação orgânica geral devida a quadro infeccioso pregresso e inatividade física durante alguns meses. Embora haja, na literatura, observações que consignam casos de síndrome mioclonica do confluente respiratório-digestivo, em que também músculos esqueléticos do tronco e membros são atingidos, não é possível atribuir o mesmo significado aos dois grupos de movimentos descritos nesta observação, dada a diversidade existente em todos seus caracteres fundamentais.

Não obstante a impossibilidade de objetivar o diagnóstico topográfico, por falta de dados anatômicos, os elementos de ordem clínica permitem supor a existência de mais de uma lesão: hemiplegia direita e afasia são a expressão de comprometimento córtico-subcortical no hemisfério cerebral esquerdo; as nioclonias velo-faringo-laríngeas à esquerda falam a favor de lesão no contingente olivo-denteado, que compreende a oliva bulbar direita, núcleo denteado cerebral esquerdo e suas vias de associação; finalmente, a presença do reflexo de retração da cabeça indica, segundo Wartenberg ${ }^{3}$, lesão bilateral do tracto corticospinal em seu segmento encefálico, ou seja, supracervical.

Rua Très Rios, $232-S$. Prulo

3. Wartenberg, R. - Head retraction reflex. Am. J. M. Sc. 201:553-561 (abril) 1941. 